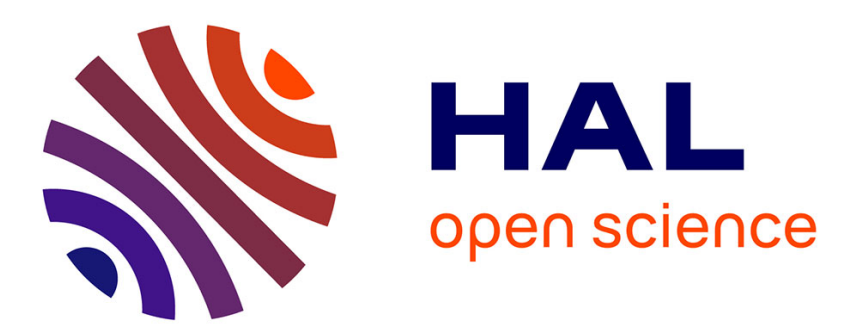

\title{
ON-state reliability of GaN-on-Si Schottky Barrier Diodes: Si3N4 vs. Al2O3/SiO2 GET dielectric
}

\author{
Eliana Acurio, Lionel Trojman, Brice de Jaeger, Benoit Bakeroot, Stefaan
}

Decoutere

\section{- To cite this version:}

Eliana Acurio, Lionel Trojman, Brice de Jaeger, Benoit Bakeroot, Stefaan Decoutere. ON-state reliability of GaN-on-Si Schottky Barrier Diodes: Si3N4 vs. Al2O3/SiO2 GET dielectric. IEEE International Reliability Physics Symposium (IRPS 2021), Mar 2021, Monterey (virtual conference), United States. pp.1-6, 10.1109/IRPS46558.2021.9405163 . hal-03218246

\section{HAL Id: hal-03218246 \\ https://hal.science/hal-03218246}

Submitted on 5 May 2021

HAL is a multi-disciplinary open access archive for the deposit and dissemination of scientific research documents, whether they are published or not. The documents may come from teaching and research institutions in France or abroad, or from public or private research centers.
L'archive ouverte pluridisciplinaire HAL, est destinée au dépôt et à la diffusion de documents scientifiques de niveau recherche, publiés ou non, émanant des établissements d'enseignement et de recherche français ou étrangers, des laboratoires publics ou privés. 


\section{ON-state reliability of GaN-on-Si Schottky Barrier Diodes: $\mathrm{Si}_{3} \mathrm{~N}_{4}$ vs. $\mathrm{Al}_{2} \mathrm{O}_{3} / \mathrm{SiO}_{2}$ GET dielectric}

\author{
Eliana Acurio \\ Physics Department, IMNE \\ Escuela Politécnica Nacional, \\ Universidad San Francisco de Quito \\ Quito,Ecuador \\ eliana.acurio@epn.edu.ec
}

\author{
Benoit Bakeroot \\ CMST \\ imec \& Ghent University \\ Ghent, Belgium \\ Benoit.Bakeroot@ugent.be
}

\author{
Lionel Trojman \\ LISITE, IMNE \\ Institut d'Electronique de Paris Isep, \\ Universidad San Francisco de Quito \\ Paris, France; Quito, Ecuador \\ lionel.trojman@isep.fr
}

\author{
Brice de Jaeger \\ imec \\ Leuven, Belgium \\ Brice.DeJaeger@imec.be
}

\author{
Stefaan Decoutere \\ imec \\ Leuven, Belgium \\ Stefaan.Decoutere@imec.be
}

\begin{abstract}
The degradation of Schottky Barrier Diodes (SBDs) with a Gated Edge Termination (GET) under on-state stress conditions is studied for a $650 \mathrm{~V}$ GaN-on-Si technology. Reliability metric techniques previously used in MOS-HEMTs are applied in this work due to similar MIS gate stack architecture in GET-SBDs. In these techniques, the density of traps $\left(\Delta \mathbf{N}_{\mathrm{OT}}\right)$ is analyzed in GET structures where the dielectric is either $\mathrm{Si}_{3} \mathrm{~N}_{4}$ (nitride-based) or a stack of $\mathrm{Al}_{2} \mathrm{O}_{3} / \mathrm{SiO}_{2}$ (oxidebased). Statistical analysis across both wafers indicates some systematic differences in turn-on voltage degradation $\left(\Delta \mathbf{V}_{\text {TON }}\right)$ depending on wafer location, likely caused by process-related variations. Under $1000 \mathrm{~s}$ stress time and $\mathrm{ON}$-state voltage, the number of trapped charges in nitride-based dielectric devices keeps increasing. This suggests an ongoing dielectric degradation. On the other hand, $\mathrm{Al}_{2} \mathrm{O}_{3} / \mathrm{SiO}_{2}$ dielectric devices with an Al-based interfacial layer (IL) exhibit less processinduced variability across the wafer along with a lower density of trapped charges compared with nitride-based dielectric diodes under the same stress conditions suggesting better reliability and process improvement.
\end{abstract}

Index Terms-- de-trapping, GaN, interfacial layer, nitride, onstate, oxide, trapping rate.

\section{INTRODUCTION}

The rapid development of power electronics applications requires advanced devices to improve the efficiency and the power density of conversion systems. In the last years, devices based on gallium nitride $(\mathrm{GaN})$ have been considered attractive and promising in this field due to their wide bandgap $(\sim 3.4 \mathrm{eV})$ and high values of breakdown voltage $(\sim 3 \mathrm{MV} / \mathrm{cm})$, saturation velocity, sheet carrier density, and electron mobility in the 2-D electron gas (2-DEG) quantum well formed at the $\mathrm{AlGaN} / \mathrm{GaN}$ heterojunction [1]. Despite the potential of this material, its widespread adoption in the power market is still limited due to reliability issues that are not yet fully understood. Several studies have been performed in different GaN-based structures to comprehend the degradation phenomena and to analyze long-term reliability [2], [3], [4].
However, the lack of consensus about the failure mechanisms needs more research on this topic.

Some of the requirements of GaN-based power diodes include high breakdown voltage $\left(\mathrm{V}_{\mathrm{BD}}\right)$ and low values of turnON voltage $\left(\mathrm{V}_{\text {TON }}\right)$, specific ON-resistance $\left(\mathrm{R}_{\mathrm{ON}, \mathrm{sp}}\right)$, and reverse leakage current. Therefore, several processing approaches have been implemented to improve the performance of $\mathrm{GaN}$-on-Si rectifiers. One of these is the introduction of a $\mathrm{Si}_{3} \mathrm{~N}_{4}$ layer at the corner of the Schottky contact to create a gated edge termination (GET) that reduces the electric field peak in this corner and the reverse current [5]. Reliability improvements under OFF-state stress conditions have been obtained in this structure by thinning the passivation layer and by employing a more aggressive preclean process based on sulfuric acid and hydrogen per- oxide mixture (SPM) and ammonia and hydrogen peroxide mixture (APM) [6]. This improved structure was fabricated in a $200-\mathrm{V}$ GaN-on-Si platform and tested under ON-state stress conditions. The results demonstrated a recoverable behavior with better reliability and longer lifetime expectation compared to previous works in 200-V technology [7]. Although promising results were obtained, a clear method to link the process to the reliability in $\mathrm{ON}$-state regime is missing. This makes the analysis highly dependent on the fabrication instead of physics mechanisms.

This paper aims to study the reliability of the aforementioned improved structure for $650 \mathrm{~V} \mathrm{GaN}$ technology. It is worth reminding that the GET resembles a metalinsulator-semiconductor structure bringing about material compatibility concerns at the semiconductor AlGaNbarrier/dielectric interface. In-situ defects at this interface may be critical as in MOS-like devices (MOSFET or MOS-HEMT) [2], [8]. Therefore, it is reasonable to apply reliability techniques (e.g. positive bias temperature instability-PBTI) and metrics like the ones successfully applied to MOSFETs. By using these metrics, it is possible to assess the number of defect centers in the insulator/oxide layer or far from the interface. More specific estimation of interface defects require 


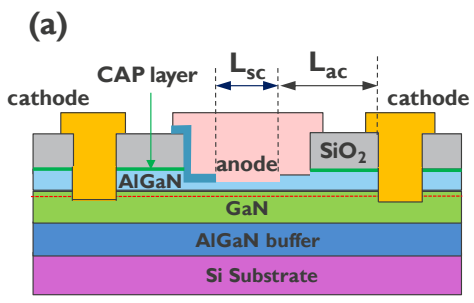

(b) N-BASED DIELECTRIC

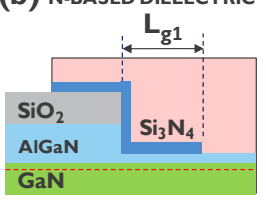

(c) O-BASED DIELECTRICS

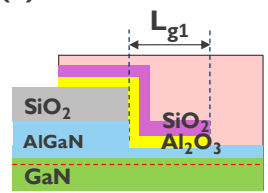

Fig. 1. Simplified schematics of (a) GET-SBDs used for ON-state stress analysis. Gate stack architecture with $\mathrm{Si}_{3} \mathrm{~N}_{4}$ (b) and $\mathrm{Al}_{2} \mathrm{O}_{3} / \mathrm{SiO}_{2}$ (c).

other techniques [9], [10], and are not included in this work. We also show a comparative study of this architecture by using a nitrogen-based dielectric made of $45 \mathrm{~nm}$ of $\mathrm{Si}_{3} \mathrm{~N}_{4}$ and an oxide-based dielectric made of $35 \mathrm{~nm}$ of $\mathrm{SiO}_{2}$ deposited onto an interfacial layer of $\mathrm{Al}_{2} \mathrm{O}_{3}(2.5 \mathrm{~nm})$.

The remainder of this paper is organized as follows. Section II presents details of the devices under test. Section III explains the experimental procedure. ON-state stress results are discussed in Section IV. Finally, the conclusions of this paper are summarized in Section V.

\section{DEVICE FABRICATION}

The schematic structure of the $\mathrm{AlGaN} / \mathrm{GaN}$ diodes studied in this paper is depicted in Fig. 1(a). The epitaxial stack is grown on a $\mathrm{Si}$ (111) substrate by means of metal-organic chemical vapour deposition (MOCVD). It features a thick superlattice buffer designed for a 650-V platform technology with a 300-nm-thick GaN channel, a 0.5-nm-thick AlN spacer, a 10-nm-thick $\mathrm{Al}_{0.25} \mathrm{Ga}_{0.75} \mathrm{~N}$ barrier, and a 5-nm-thick SiN cap. The epitaxial stack is passivated with a $\mathrm{SiO}_{2}$ layer using hightemperature oxide deposition.

In the anode region, the passivation layer is removed by dry etch and the barrier is recessed by about $\sim 6 \mathrm{~nm}$ using atomic layer etching. The GET reference structure has a nitrogen (N)-based dielectric, which is formed by depositing a 45-nm-thick $\mathrm{Si}_{3} \mathrm{~N}_{4}$ layer by means of plasma-enhanced atomic layer deposition (PEALD). A subsequent opening by dry etching in the central region defines the actual Schottky contact with a length Lsc $=4 \mu \mathrm{m}$, an edge termination length $\mathrm{L}_{\mathrm{g} 1}=2 \mu \mathrm{m}$ and an anode-to-cathode distance $\mathrm{L}_{\mathrm{ac}}=16 \mu \mathrm{m}$ as illustrated in Fig. 1(b). An Au-free TiN-based metal stack is then deposited and etched to form the Schottky contact at the anode region [5]. Finally, the ohmic contacts are processed using a Ti/Al-based metal stack with an alloying temperature of $565^{\circ} \mathrm{C}$.

For this comparative study, a second wafer was fabricated with a bilayer in the GET region, which includes an oxide (O)based dielectric as shown in Fig. 1(c). For this structure, a 2.5nm-thick interfacial layer (IL) of $\mathrm{Al}_{2} \mathrm{O}_{3}$ was deposited by atomic layer deposition followed by a 35-nm-thick layer of $\mathrm{SiO}_{2}$ deposited by means of plasma-enhanced chemical vapour deposition (PECVD).

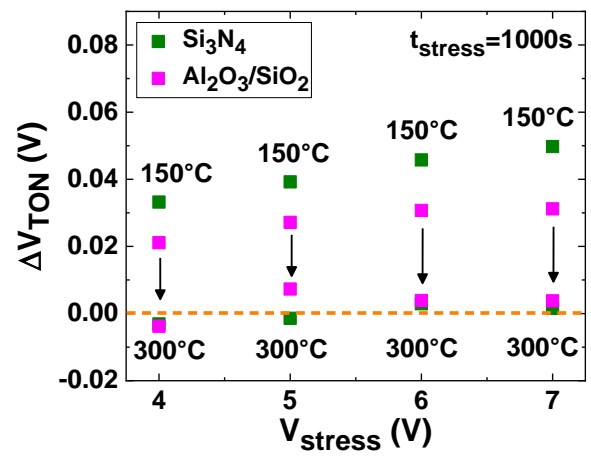

Fig. 2. Total $\Delta \mathrm{V}_{\text {TON }}$ after $1000 \mathrm{~s}$ of stress at $150^{\circ} \mathrm{C}$ and the recovery of the initial state after a thermal de-trapping (TD) process at $300^{\circ} \mathrm{C}$ in $\mathrm{Si}_{3} \mathrm{~N}_{4}$ and $\mathrm{Al}_{2} \mathrm{O}_{3} / \mathrm{SiO}_{2}$ dielectric devices.

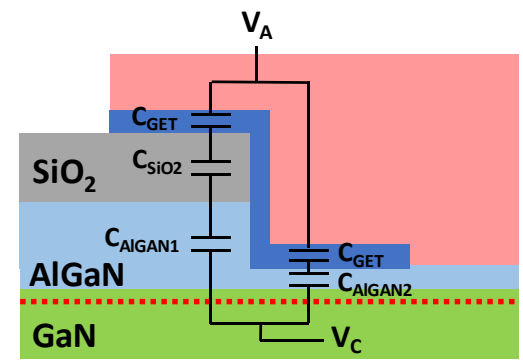

Fig. 3. Schematic model to obtain $\mathrm{C}_{\text {eff }}$ which is $0.18 \mu \mathrm{F} / \mathrm{cm}^{2}$ and 0.13 $\mu \mathrm{F} / \mathrm{cm}^{2}$ for $\mathrm{Si}_{3} \mathrm{~N}_{4}$ and $\mathrm{Al}_{2} \mathrm{O}_{3} / \mathrm{SiO}_{2}$, respectively.

\section{EXPERIMENTAL PROCEDURE}

The technique to assess the dielectric reliability for GETSBDs starts with an initial stabilization phase in which a voltage $(6 \mathrm{~V})$ is applied at high temperature $\left(150{ }^{\circ} \mathrm{C}\right)$ followed by a thermal de-trapping (TD) with floating contacts at 300 ${ }^{\circ} \mathrm{C}$. This procedure releases charges originally trapped in defect centers within the GET dielectric and captures the real degradation under the stress conditions. It is worth noting that the I-V curves almost overlap the fresh I-V curves (not shown for the sake of brevity) after the stabilization for the $\mathrm{Al}_{2} \mathrm{O}_{3} / \mathrm{SiO}_{2}$ devices, which indicates lower amount of initially trapped charges. Subsequently, during the stress phase, the devices are biased with a positive anode-to-cathode stress voltage $\left(\mathrm{V}_{\text {stress }}\right)$ ranging between $4 \mathrm{~V}$ and $7 \mathrm{~V}$. To capture the degradation, the stress was interrupted at fixed time intervals (Measure-Stress-Measure technique MSM) up to 1000 s. An I$\mathrm{V}$ curve was measured and compared with the fresh (reference) one obtained in the stabilization phase to calculate the ON-state threshold voltage shift $\left(\Delta \mathrm{V}_{\mathrm{TON}}\right)$, which for these structures is always positive indicating an electron trapping process. Finally, the thermal-de-trapping process $\left(300{ }^{\circ} \mathrm{C}\right)$ is applied again to release the trapped charges during the stress and to prepare devices for subsequent experiments. It is worth highlighting that after the thermal de-trapping (TD) process following the stress phase, the diodes can almost completely recover from the stress-induced degradation during the experiments. A small non zero $\Delta \mathrm{V}_{\mathrm{TON}}$ is observed in Fig. 2 and could be explained by a permanent component residue. This procedure was performed in 64 diodes across the wafers.

The $\Delta \mathrm{V}_{\mathrm{TON}}$ is directly related to the trapped charge density $\Delta \mathrm{N}_{\text {OT }}$ through: 


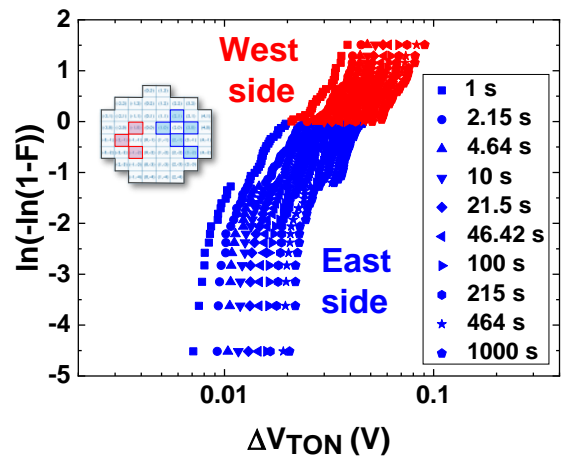

Fig. 4. Weibull distributions of $\Delta \mathrm{V}_{\text {TON }}$ at $\mathrm{V}_{\text {stress }}=6 \mathrm{~V}$ and $\mathrm{T}=150^{\circ} \mathrm{C}$ in $\mathrm{Si}_{3} \mathrm{~N}_{4}$ dielectric devices. Two trends are observed depending on the wafer location.
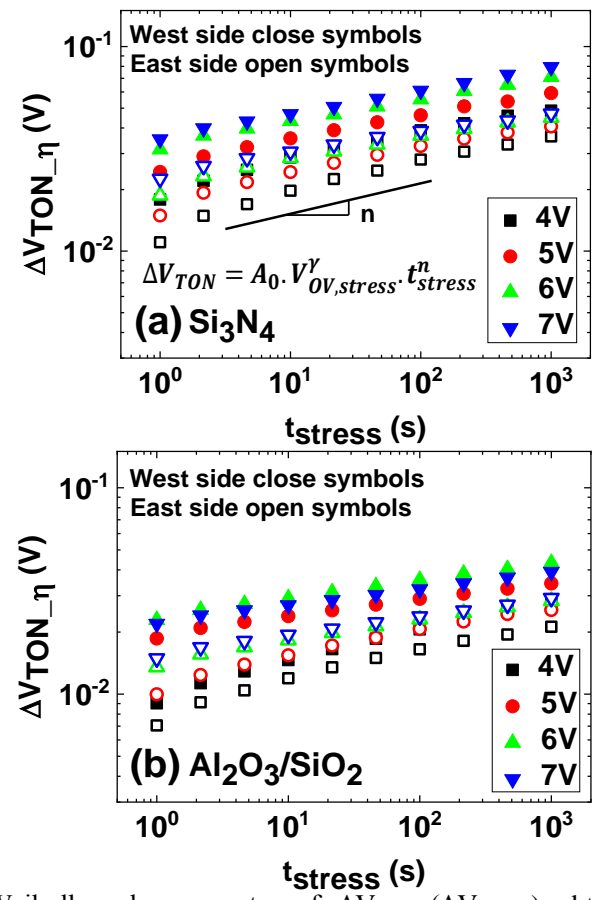

Fig. 5. Weibull scale parameter of $\Delta \mathrm{V}_{\mathrm{TON}}\left(\Delta \mathrm{V}_{\mathrm{TON}_{\eta}}\right)$ obtained under different stress voltages as function of the stress time for (a) $\mathrm{Si}_{3} \mathrm{~N}_{4}$ and (b) $\mathrm{Al}_{2} \mathrm{O}_{3} / \mathrm{SiO}_{2}$ diodes, respectively. These measurements were performed at 150 or

$$
\Delta N_{O T}=\left(C_{e f f} * \Delta V_{T O N}\right) / q
$$

where $C_{e f f}$ is the effective capacitance per unit area that has been obtained with the electrical model in Fig. 3 and $q$ is the elementary charge. This model focuses on the region around $\mathrm{V}_{\text {TON }}$ where the capacitance remains fixed [11].

\section{RESULTS AND DISCUSSION}

The degradation results under ON-state stress show two different probability trends according to the wafer location. An approximately twice higher degradation is observed on the west side compared to the east side of the wafer, which can be attributed to process-induced or systematic variability under large forward stress. Indeed, stress voltages from $4 \mathrm{~V}$ to $7 \mathrm{~V}$ were applied to the anode-cathode contact which is well above the usual operating forward voltage for these devices, namely $\mathrm{V}_{\mathrm{F}}=1.83 \mathrm{~V}$ and $1.74 \mathrm{~V}$ for the $\mathrm{N}$-based and O-based dielectric devices, respectively. More explanation about this observation was reported in our previous work [7]. In both cases, a Weibull distribution is found to fit well the data. Fig. 4 shows
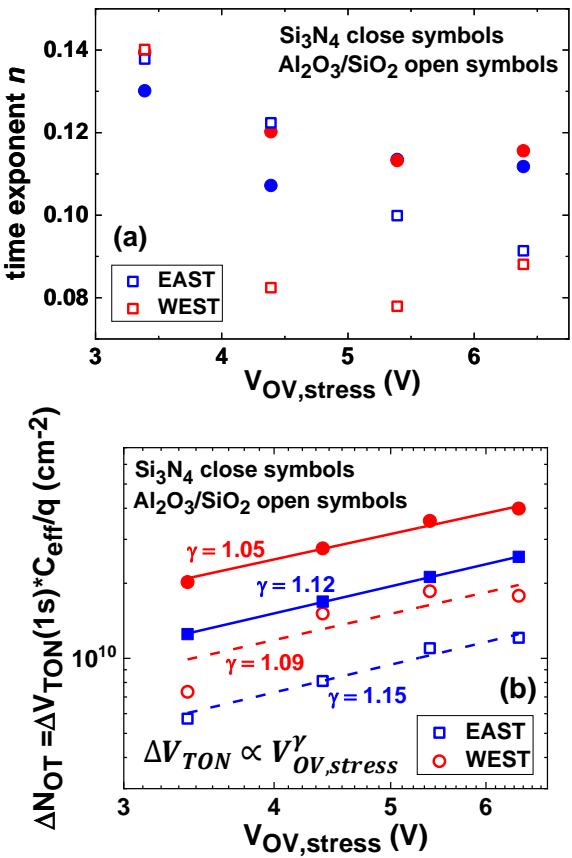

Fig. 4. (a) Time exponent $n$ and (b) $\Delta \mathrm{N}_{\mathrm{OT}}$ as a function of the $\mathrm{V}_{\mathrm{OV} \text {,stress. }}$

an example for a stress voltage $\mathrm{V}_{\text {stress }}=6 \mathrm{~V}$. Similar results were obtained for all experiments.

\section{A. Nonlinear dependence model}

From the Weibull distributions, the scale parameter $(\eta)$ is plotted vs. stress time in Fig. $5\left(\Delta \mathrm{V}_{\text {TON } \eta}\right)$ for different stress conditions. Large forward stress in the $\mathrm{ON}$-state regime produces $\Delta \mathrm{V}_{\text {TON }}$ shifts in the range from 5 to $100 \mathrm{mV}$.

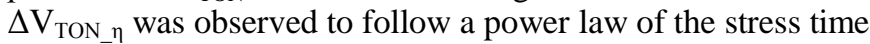
and stress overdrive voltage and the data fit well with the model proposed in [8]:

$$
\Delta V_{T O N_{-} \eta}=A_{0} \cdot V_{O V, \text { stress }}{ }^{\gamma} \cdot t_{\text {stress }}^{n}
$$

where $A_{0}$ is the prefactor, $n$ is the time exponent, $\gamma$ is the voltage dependence exponent and $\mathrm{V}_{\mathrm{OV} \text {,stress }}$ is the difference between the stress voltage and the initial measured $\mathrm{V}_{\mathrm{TON}}$ :

$$
\left(V_{O V, \text { stress }}=\left|V_{\text {stress }}-V_{\text {TON_initial }}\right|\right) \text {. }
$$

As depicted in Fig. 6 (a), the extracted time exponent $n$ exhibits a decreasing behavior with $\mathrm{V}_{\mathrm{OV} \text {,stress }}$ independently of the GET dielectric $\mathrm{Si}_{3} \mathrm{~N}_{4}$ or $\mathrm{Al}_{2} \mathrm{O}_{3} / \mathrm{SiO}_{2}$. Moreover, its range agree with BTI reports in different technologies [8], [12], [13].

The trapped charge density $\Delta \mathrm{N}_{\text {OT }}$ is extracted after 1-s stress in Fig 6 (b), by using (1). The value of the voltage dependence exponent $\gamma$ about 1 (east side) and 1.15 (west side) suggests the existence of a wide distribution of defect levels centered around the channel Fermi level [8]. This indicates similar accessibility to the dielectric defects in both types of GET dielectrics.

It is worth mentioning that $\Delta \mathrm{V}_{\mathrm{TON}}$ evolution during the stress can also be expressed by using a semi empirical model [13]: 

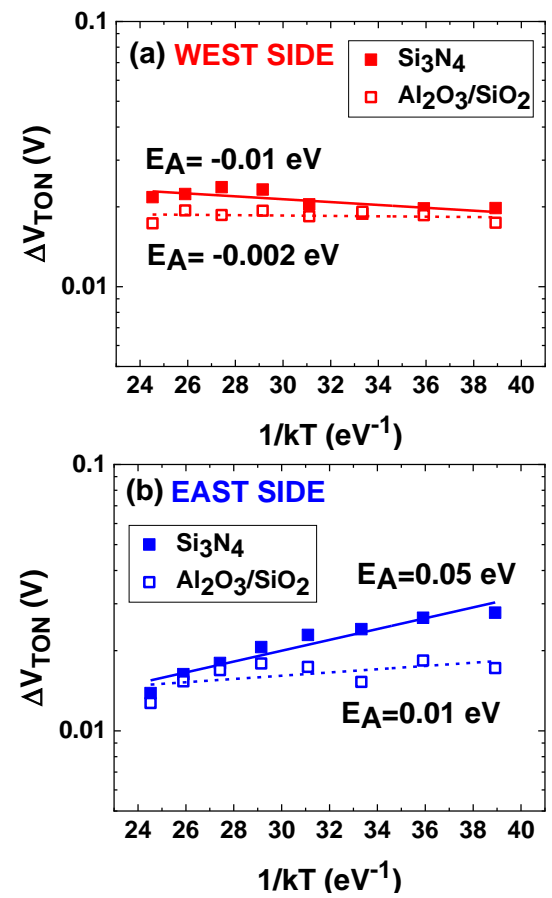

Fig. 7. Arrhenius plots of $\Delta \mathrm{V}_{\text {TON }}$ on (a) west- and (b) east-side devices. The $\Delta \mathrm{V}_{\text {TON }}$ values were extrapolated when the devices were stressed at $4 \mathrm{~V}$ for $1 \mathrm{~s}$.
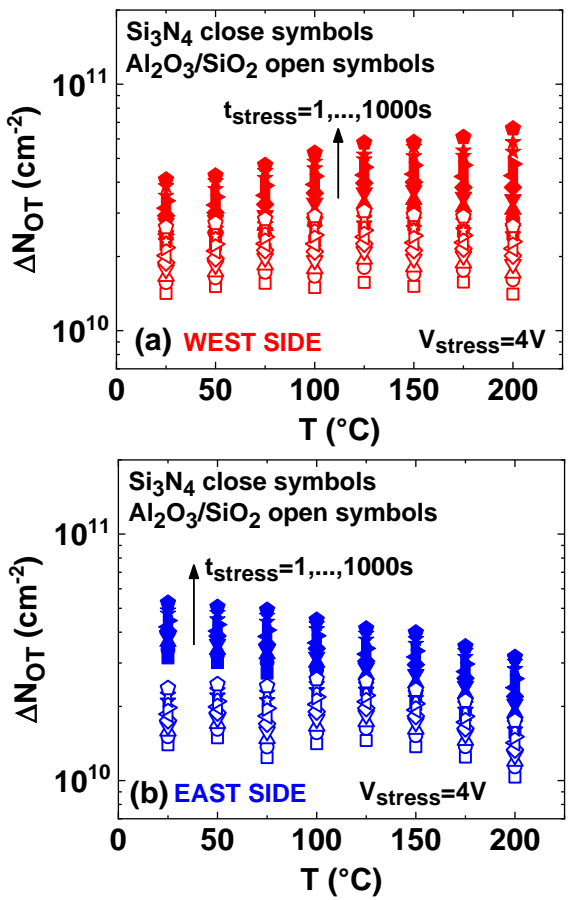

Fig. 8. $\Delta \mathrm{N}_{\mathrm{OT}}$ as a function of temperature on (a) west- and (b) east-side devices.

(4)

$$
\Delta V_{T O N_{-} \eta} \approx \exp \left(-E_{A} / k_{B} T\right)\left(V_{O V, \text { stress }} / t_{o x}\right)^{\gamma} t_{\text {stress. }}^{n}
$$

The apparent $\Delta \mathrm{V}_{\text {TON }}$ activation energies are extracted by fitting an exponential trend in the Arrhenius plots as depicted in Fig. 7. To assess the mean activation energy of the charge capture process, it is necessary to consider the time to reach a given $\Delta \mathrm{V}_{\mathrm{TON}}$. Therefore, the apparent activation energy is divided for the time exponent $n$. The mean activation energies
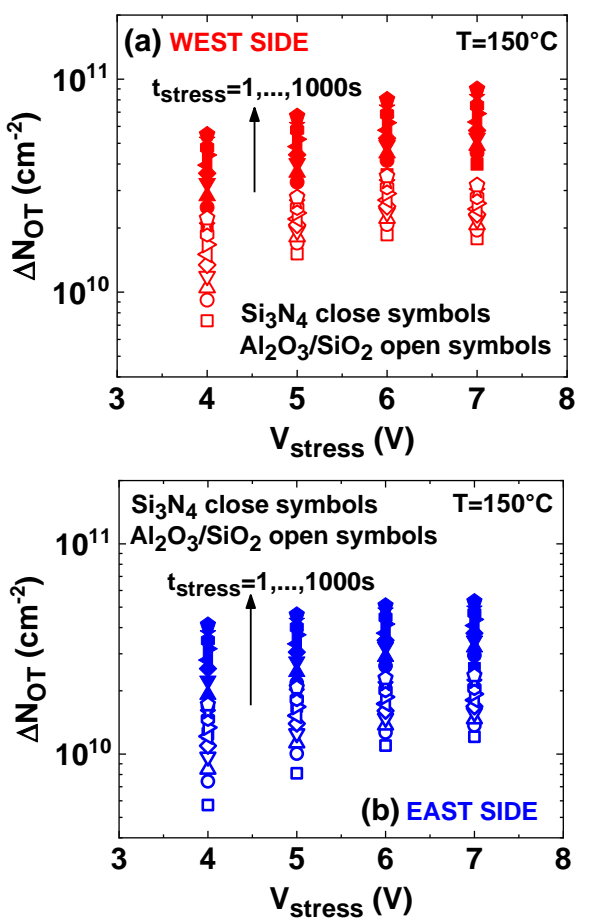

Fig. 9. $\Delta \mathrm{N}_{\mathrm{OT}}$ as a function of stress voltage on (a) west- and (b) east-side devices.

in west-side devices were estimated to be $-0.072 /-0.014 \mathrm{eV}$ ( $n$ is $0.139 / 0.140$ ) for $\mathrm{Si}_{3} \mathrm{~N}_{4}$ and $\mathrm{Al}_{2} \mathrm{O}_{3} / \mathrm{SiO}_{2}$ GET dielectrics, respectively. In the case of east-side devices, the values were $0.384 / 0.073 \mathrm{eV}$ ( $n$ is $0.130 / 0.138$ ).

By considering the database of the deep levels in $\mathrm{GaN}$ - and AlGaN-based devices [14], such low values can be ascribed to nitrogen vacancies. The relatively high value of $0.384 \mathrm{eV}$ in $\mathrm{Si}_{3} \mathrm{~N}_{4}$ devices in the east side can be possibly related to $\mathrm{AlGaN}$ surface.

Temperature and stress voltage conditions in Fig. 8 and 9, respectively, show different reliabilities and variabilities depending on the GET dielectric. For the $\mathrm{Si}_{3} \mathrm{~N}_{4}$ GET-SBDs, $\Delta \mathrm{N}_{\mathrm{OT}}$ is lowered for the east-side devices suggesting a detrapping phenomenon enhanced by temperature while the west-side devices show the opposite trend. On the other hand, the temperature has a low influence in the trapping and detrapping process in $\mathrm{Al}_{2} \mathrm{O}_{3} / \mathrm{SiO}_{2}$ dielectric independently of the side of the wafer. As a result, the $\mathrm{Si}_{3} \mathrm{~N}_{4}$ dielectric produces more trapping phenomena with larger variability than $\mathrm{Al}_{2} \mathrm{O}_{3} / \mathrm{SiO}_{2}$ devices under the same stress conditions (Fig. 8 and 9), yet with similar activation energies as previously shown in Fig. 7.

\section{B. Trapping rate parameter analysis}

To gain insight into the $\Delta \mathrm{V}_{\mathrm{TON}}$ behavior for these different devices, the time exponent $n$ is evaluated as a function of the stress time:

$$
n\left(t_{\text {stress }}\right)=b=\partial \log \Delta V_{\text {TON }} / \partial \log t_{\text {stress }}
$$

where $\mathrm{b}$ is the so-called trapping rate or b-parameter [2].

The b-parameter measures the evolution of the ratio between the trapping and de-trapping mechanisms under 

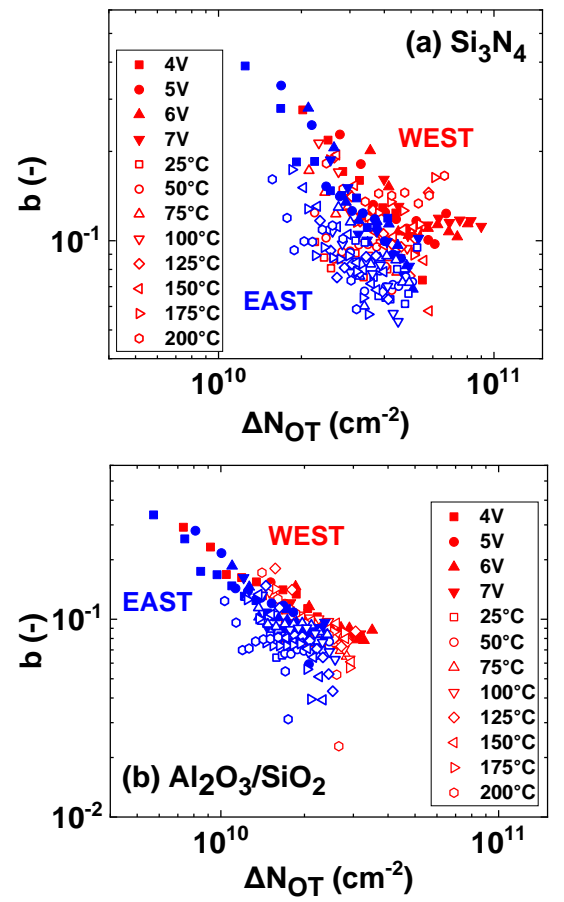

Fig. 10. b-parameter as a function of the $\Delta \mathrm{N}_{\mathrm{OT}}$ in (a) $\mathrm{Si}_{3} \mathrm{~N}_{4}$ and (b) $\mathrm{Al}_{2} \mathrm{O}_{3} / \mathrm{SiO}_{2}$ GET-SBDs. Stress voltage and stress temperature experiments were performed at $150{ }^{\circ} \mathrm{C}$ and $4 \mathrm{~V}$, respectively.

given stress voltage and temperature conditions. This parameter is plotted in Fig. 10 as a function of the defect density $\left(\Delta \mathrm{N}_{\mathrm{OT}}\right)$ for all stress conditions. As illustrated in Fig. 10 (a), the $\mathrm{Si}_{3} \mathrm{~N}_{4}$ devices have a significant variability across the wafer. The west-side devices exhibit larger trapping density compared to the east side (maximum of around $4.10^{10}$ $\mathrm{cm}^{-2}$ ) and this density even increases with larger stress voltages $(6-7 \mathrm{~V})$ and temperatures, which indicates further trapping of charges under these stress conditions. This different behavior between east- and west-side devices confirms the variability of the wafer observed in the first place.

For $\mathrm{Al}_{2} \mathrm{O}_{3} / \mathrm{SiO}_{2}$ devices, Fig. 10 (b) shows much more uniformity or less variability across the wafer. The $\Delta \mathrm{N}_{\mathrm{OT}}$ is limited to a fixed value of about $2-3 \cdot 10^{10} \mathrm{~cm}^{-2}$. A somewhat lower density of traps is reached for the east-side devices.

It is important to mention that an important $\Delta \mathrm{N}_{\mathrm{OT}}$ increase (kink) under harsh stress conditions, especially in $\mathrm{Si}_{3} \mathrm{~N}_{4}$ devices located on the west side, is observed in Fig. 10 (a). This indicates that the amount of trapping keeps increasing with the stress time, voltage, and temperature. In this case, this ongoing increase could suggest either deeper trapping in the dielectric material or creation of defects at the dielectric interface or within the dielectric. Although the devices exhibit an apparent recoverable behavior, where the creation of defects is not conceived, we cannot discard the possibility of a permanent degradation component that under high temperature (from $300{ }^{\circ} \mathrm{C}$ ) of the thermal de-trapping process can be reversed or "baked away" [15].

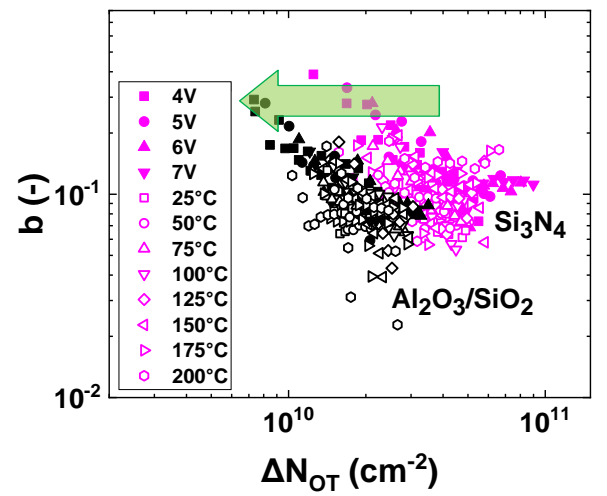

Fig. 11. $\Delta \mathrm{N}_{\text {От }}$ comparison between wafer sides under stress voltage conditions between $\mathrm{Si}_{3} \mathrm{~N}_{4}$ and $\mathrm{Al}_{2} \mathrm{O}_{3} / \mathrm{SiO}_{2}$ dielectric GET-SBDs. Lower density of traps and variability are observed for the metal-oxide bilayer.

On the contrary, for the $\mathrm{Al}_{2} \mathrm{O}_{3} / \mathrm{SiO}_{2}$ devices on the west side, the $\Delta \mathrm{N}_{\text {OT }}$ kink is less prominent suggesting that the deep trapping in the oxide is limited by the temperature detrapping process which is more efficient than for the $\mathrm{Si}_{3} \mathrm{~N}_{4}$ devices (Fig. 8 (a)).

In the east-side devices independently of the GET dielectric, $\Delta \mathrm{N}_{\text {OT }}$ saturates at high-stress voltages and decreases at high temperatures (Fig. 8 and 9). Therefore, it is possible to say that pre-existing defects at the interface/dielectric can be saturated with electrons. The longer the stress time applied, the larger the number of trapped charges. At some point, the dielectric interface cannot trap any more electrons due to the de-trapping process enhanced by temperature or trapped electrons that prevent further trapping of charges within or at the border of the dielectric [16], [17].

Fig. 11 proposes a metric summarizing the specificity of the two different dielectric materials: stress voltage dependence, trapping/de-trapping rate and interface quality. It shows important correlations between the $\Delta \mathrm{N}_{\text {От }}$ increase, the trapping rate, and the variability across the wafer. For the same b-parameter values, $\Delta \mathrm{N}_{\text {OT }}$ is lower for $\mathrm{Al}_{2} \mathrm{O}_{3} / \mathrm{SiO}_{2}$ compared to $\mathrm{Si}_{3} \mathrm{~N}_{4}$ GET dielectric. From low to large stress conditions, it can be noted that the variability is increased as demonstrated by the increased data scattering for large $\Delta \mathrm{N}_{\mathrm{OT}}$, especially for the $\mathrm{Si}_{3} \mathrm{~N}_{4}$ dielectric. Also, and more importantly, under larger stress voltage (7V), the $\mathrm{Al}_{2} \mathrm{O}_{3} / \mathrm{SiO}_{2}$ devices do not increase $\Delta \mathrm{N}_{\text {OT }}$ as it is the case of the $\mathrm{Si}_{3} \mathrm{~N}_{4}$ devices, especially in west-side devices. It is worth mentioning that the amount of trapping for both dielectrics remains low: even for the $\mathrm{Si}_{3} \mathrm{~N}_{4}$ with larger variability, $\Delta \mathrm{N}_{\text {От }}$ stays below $10^{11} / \mathrm{cm}^{2}$ under large forward stress voltage.

For both types of dielectrics, we assume that the defects are mostly located at the dielectric /AlGaN interface. Indeed, we can suggest that the increase of trapped electrons indicates deeper trapping in the dielectric or a generation of defects that must be located in a region of the gate dielectric which exhibits weak atomic bonds. This can be a material defect where the atomic compatibility is not fully ensured. For instance, the trapped electrons on the interface could build a 


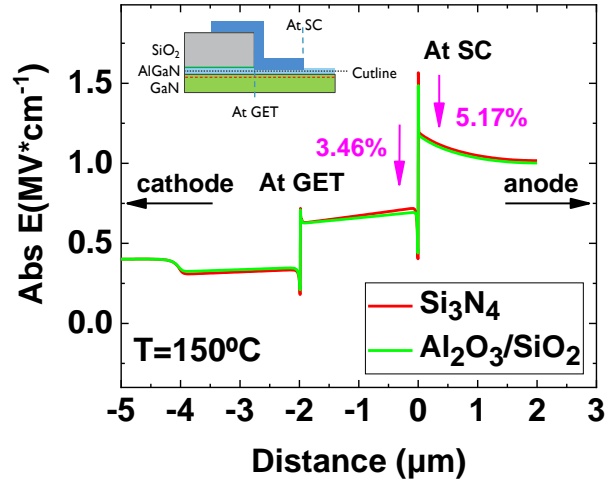

Fig. 12. Line profile of the absolute electric field within the AlGaN barrier ( $3 \mathrm{~nm}$ below the top surface in the recessed portion) for N-based and Obased dielectric GET-SBDs. The IL helps reducing the electric field at the gate.

potential barrier preventing deep trapping inside the dielectric. Therefore, we can also speculate that a constant increase of the amount of defects is present at the bottom of the gate dielectric (namely the interface with the $\mathrm{AlGaN}$ Barrier). Although these defects may be located at the interface between two materials, they are still considered as bulk or dielectric defects since they are far from the place where the current $(\mathrm{AlGaN} / \mathrm{GaN})$ is flowing. In the case of an oxide-base dielectric, an interfacial layer (IL) of $\mathrm{Al}_{2} \mathrm{O}_{3}$ is deposited on the AlGaN. Based on the reliability results in Fig. 11, we speculate that the $\mathrm{Al}_{2} \mathrm{O}_{3}$ IL deposited before the $\mathrm{SiO}_{2}$ may enable better compatibility between the $\mathrm{SiO}_{2}$ and the AlGaN barrier, and this is likely related to the use of $\mathrm{Al}$. This explains again why for large stress voltages, there is almost no generation of defects or deeper dielectric trapping at the $\mathrm{Al}_{2} \mathrm{O}_{3} / \mathrm{AlGaN}$ interface compared to the $\mathrm{Si}_{3} \mathrm{~N}_{4} / \mathrm{AlGaN}$ one.

Finally, the use of O-based IL seems also to reduce the peak of the electric field intensity at the AlGaN barrier according to the TCAD simulation as shown in Fig. 12. It may somewhat also improve the b-parameter reduction under large stress voltage. This can also be related to the use of higher-k value IL as suggested in the case of MOS-HEMTs [18].

\section{CONCLUSIONS}

In this paper, we have presented the results of ON-state stress degradation in AlGaN/GaN SBDs fabricated in a $650 \mathrm{~V}$ technology with either N-based or O-based GET dielectrics. A nonlinear dependence model and the change in density of traps $\left(\Delta \mathrm{N}_{\mathrm{OT}}\right)$ are used as reliability metrics in this work. The choice of the GET dielectric and the resulting properties of the GET dielectric/AlGaN interface are proven to be critical. Results suggest that the GET dielectric region is where the generation of defects or deeper charge trapping under high voltage stress conditions could take place. A reduced $\Delta \mathrm{N}_{\mathrm{OT}}$ for the process involving the $\mathrm{O}$-based dielectric with $\mathrm{Al}_{2} \mathrm{O}_{3} \mathrm{IL}$ is observed compared to the N-based dielectric. Better uniformity of the results across the wafer and a more stable maximum of $\Delta \mathrm{N}_{\mathrm{OT}}$ for large stress voltage (up to $7 \mathrm{~V}$ ) are also observed. Therefore, $\mathrm{Al}_{2} \mathrm{O}_{3} / \mathrm{SiO}_{2}$ dielectric yields better reliability and lower variability across the wafer suggesting a better quality of the $\mathrm{AlGaN}$-barrier/dielectric interface and more uniform process control than with $\mathrm{Si}_{3} \mathrm{~N}_{4}$ dielectric. It makes $\mathrm{ALD} \mathrm{Al}_{2} \mathrm{O}_{3} / \mathrm{PECVD} \mathrm{SiO}_{2}$ dielectric a more attractive option for the $650 \mathrm{~V}$ AlGaN/GaN SBDs technology.

\section{REFERENCES}

[1] O. Ambacher et al., "Two-dimensional electron gases induced by spontaneous and piezoelectric polarization charges in $\mathrm{N}$ - and $\mathrm{Ga}-$ face AlGaN/GaN heterostructures," J. Appl. Phys., vol. 85, no. 6, pp. 3222-3233, Mar. 1999, doi: 10.1063/1.369664.

[2] E. Acurio, F. Crupi, P. Magnone, L. Trojman, G. Meneghesso, and F. Iucolano, "On recoverable behavior of PBTI in $\mathrm{AlGaN} / \mathrm{GaN}$ MOSHEMT,” Solid. State. Electron., vol. 132, pp. 49-56, Jun. 2017, doi: 10.1016/j.sse.2017.03.007.

[3] E. Acurio et al., "Reliability in GaN-based devices for power applications," in 2018 IEEE Third Ecuador Technical Chapters Meeting (ETCM), 2018, pp. 1-6, doi: 10.1109/ETCM.2018.8580263.

[4] M. Meneghini et al., "Extensive Investigation of Time-Dependent Breakdown of GaN-HEMTs Submitted to OFF-State Stress," IEEE Trans. Electron Devices, vol. 62, no. 8, pp. 2549-2554, Aug. 2015, doi: 10.1109/TED.2015.2446032.

[5] S. Lenci et al., "Au-Free AlGaN/GaN Power Diode on 8-in Si Substrate With Gated Edge Termination," IEEE Electron Device Lett., vol. 34, no. 8, pp. 1035-1037, Aug. 2013, doi: 10.1109/LED.2013.2267933.

[6] E. Acurio et al., "Reliability Improvements in AlGaN/GaN Schottky Barrier Diodes With a Gated Edge Termination," IEEE Trans. Electron Devices, vol. 65, no. 5, pp. 1765-1770, May 2018, doi: 10.1109/TED.2018.2818409.

[7] E. Acurio, L. Trojman, F. Crupi, T. Moposita, B. De Jaeger, and S. Decoutere, "Reliability Assessment of AlGaN/GaN Schottky Barrier Diodes under ON-state stress," IEEE Trans. Device Mater. Reliab., pp. 1-1, 2020, doi: 10.1109/TDMR.2020.2969638.

[8] T.-L. Wu et al., "Toward Understanding Positive Bias Temperature Instability in Fully Recessed-Gate GaN MISFETs," IEEE Trans. Electron Devices, vol. 63, no. 5, pp. 1853-1860, May 2016, doi: 10.1109/TED.2016.2539341.

[9] C. Mizue, Y. Hori, M. Miczek, and T. Hashizume, "CapacitanceVoltage Characteristics of $\mathrm{Al} 2 \mathrm{O} 3 / \mathrm{AlGaN} / \mathrm{GaN}$ Structures and State Density Distribution at Al 2 O 3 /AlGaN Interface," Jpn. J. Appl. Phys., vol. 50, no. 2, p. 021001, Feb. 2011, doi: 10.1143/JJAP.50.021001.

[10] C. M. Jackson, A. R. Arehart, E. Cinkilic, B. McSkimming, J. S. Speck, and S. A. Ringel, "Interface trap characterization of atomic layer deposition $\mathrm{Al} 2 \mathrm{O} \quad 3 / \mathrm{GaN}$ metal-insulator-semiconductor capacitors using optically and thermally based deep level spectroscopies," J. Appl. Phys., vol. 113, no. 20, p. 204505, May 2013, doi: 10.1063/1.4808093.

[11] J. Hu et al., "Statistical Analysis of the Impact of Anode Recess on the Electrical Characteristics of AlGaN/GaN Schottky Diodes With Gated Edge Termination," IEEE Trans. Electron Devices, vol. 63, no. 9, pp. 3451-3458, Sep. 2016, doi: 10.1109/TED.2016.2587103.

[12] J. Franco et al., "Understanding the suppressed charge trapping in relaxed- and strained-Ge/SiO $<$ inf $>2</$ inf $>/ \mathrm{HfO}<$ inf $>2</$ inf $>$ pMOSFETs and implications for the screening of alternative highmobility substrate/dielectric CMOS gate stacks," in 2013 IEEE International Electron Devices Meeting, 2013, pp. 15.2.1-15.2.4, doi: 10.1109/IEDM.2013.6724634

[13] M. Cho et al., "Insight Into N/PBTI Mechanisms in Sub-1-nm-EOT Devices," IEEE Trans. Electron Devices, vol. 59, no. 8, pp. 20422048, Aug. 2012, doi: 10.1109/TED.2012.2199496.

[14] D. Bisi et al., "Deep-Level Characterization in GaN HEMTs-Part I: Advantages and Limitations of Drain Current Transient Measurements," IEEE Trans. Electron Devices, vol. 60, no. 10, pp. 3166-3175, Oct. 2013, doi: 10.1109/TED.2013.2279021.

[15] T. Grasser et al., "The 'permanent' component of NBTI revisited: Saturation, degradation-reversal, and annealing," in 2016 IEEE International Reliability Physics Symposium (IRPS), 2016, vol. 2016Septe, pp. 5A-2-1-5A-2-8, doi: 10.1109/IRPS.2016.7574504.

[16] P. Lagger, C. Ostermaier, and D. Pogany, "Enhancement of Vth drift 
for repetitive gate stress pulses due to charge feedback effect in GaN MIS-HEMTs," in 2014 IEEE International Reliability Physics Symposium, 2014, no. c, pp. 6C.3.1-6C.3.6, doi: 10.1109/IRPS.2014.6861110.

[17] P. Lagger, M. Reiner, D. Pogany, and C. Ostermaier, "Comprehensive Study of the Complex Dynamics of Forward Bias-Induced Threshold Voltage Drifts in GaN Based MIS-HEMTs by Stress/Recovery Experiments," IEEE Trans. Electron Devices, vol. 61, no. 4, pp. 1022-
1030, Apr. 2014, doi: 10.1109/TED.2014.2303853.

[18] H. Hanawa, H. Onodera, A. Nakajima, and K. Horio, "Numerical Analysis of Breakdown Voltage Enhancement in AlGaN/GaN HEMTs With a High-\$k\$ Passivation Layer," IEEE Trans. Electron Devices, vol. 61, no. 3, pp. 769-775, Mar. 2014, doi: 10.1109/TED.2014.2298194. 